\title{
Comparing Lipid Levels of Smokers and Non- smokers in Sagamu, South-West, Nigeria
}

\author{
Emmanuel O. Taiwo ${ }^{1 *}$, Lateef OA. Thanni ${ }^{2}(\mathbb{0}$ \\ 'Department of Physiology, Obafemi Awolowo College of Health Sciences, Olabisi Onabanjo University, Ago Iwoye, \\ Nigeria \\ ${ }^{2}$ Department of Surgery, Obafemi Awolowo College of Health Sciences, Olabisi Onabanjo University, Ago Iwoye, \\ Nigeria
}

*Corresponding Author: Emmanuel O. Taiwo, M.D., Department of Physiology, Obafemi Awolowo College of Health Sciences, Olabisi Onabanjo University, Ago Iwoye, Nigeria. Tel: +234-08034719883, Email: taiwobmc2010@yahoo.com

Received June 3, 2020; Accepted January 18, 2021; Online Published February 13, 2021

\begin{abstract}
Background: Serum lipid levels are known to be affected by the level of smoking of individuals in an environment. The prevalence of current smokers in Nigeria is $10.4 \%$.

Objectives: This study aimed to assess the blood lipid levels of selected people of Sagamu, Nigeria.

Methods: This study involved 100 subjects selected using random sampling method in Sagamu, aged 25 to 54 years. Hypertensive and Diabetic subjects were exempted. The weight in $\mathrm{kg}$ and height in meters of each subject were measured. The body mass index (BMI) $\left(\mathrm{kg} / \mathrm{m}^{2}\right)$ was calculated. Lipid profile (LP) was determined by analytical method. Data were analyzed using descriptive statistics.

Results: There were 80 males and 20 females in the study population. $40(80.0 \%)$ males and $10(20.0 \%)$ females were smokers in the study group. There were 24 (48.0\%) smokers and 27 (54.0\%) non-smokers in the age group 25 and 34 years. Two (4.0\%) smokers of the study group were obese while $4(8.0 \%)$ were obese non-smokers. Eighteen (36.0\%) smokers and $14(28.0 \%)$ non-smokers were overweight. The average total cholesterol (TC) of $198.71 \pm 2.30 \mathrm{mg} / \mathrm{dL}$ in smokers was significantly greater than $174.62 \pm 1.51$ $\mathrm{mg} / \mathrm{dL}$ in non-smokers $(P<0.05)$. The mean high-density lipoprotein $(\mathrm{HDL})$ of $56.74 \pm 1.15 \mathrm{mg} / \mathrm{dL}$ in non-smokers was significantly higher than $40.87 \pm 1.32 \mathrm{mg} / \mathrm{dL}$ in smokers $(P<0.05)$. The average TC of $195.38 \pm 2.22 \mathrm{mg} / \mathrm{dL}$ in male smokers was significantly greater than $166.04 \pm 1.51 \mathrm{mg} / \mathrm{dL}$ in male non-smokers $(P<0.05)$.

Conclusion: The HDL levels in smokers are lower than non-smokers. Low-density lipoprotein (LDL), triglycerides (TG), and TC in smokers are however higher. The lipid levels of smokers gotten from this study can be used as a baseline for future study.

Keywords: Lipids, Body Weight, Smokers, Non-Smokers, BMI
\end{abstract}

\section{Background}

It has long been known that smokers compared to nonsmokers have a lower concentration of high density lipoprotein cholesterol (HDL-C). ${ }^{1,2}$ There is proof that ex-smokers compared to current smokers (US surgeon general on health) have higher HDL-C concentrations. ${ }^{3}$ Each year, smoking leads to 443,000 smoking-related deaths in the United States, and approximately $20 \%$ of all coronary heart disease deaths can be related to smoking., Even though the robust relationship between smoking and cardiovascular disease (CVD) has well been documented, ${ }^{6,7}$ the mechanisms by which smoking enhances CVD risk seem to be multifactorial and incompletely understood, in part since these associations have been derived from observational studies. ${ }^{8,11}$ These studies, and smaller clinical trials, suggest that cigarette smoking is associated with a more atherogenic lipid profile (LP), ${ }^{11}$ characterized by higher total cholesterol (TC) and triglycerides (TG) with lower levels of HDL-C. ${ }^{9,10}$
The intensity of smoking also has been related to small, statistically significant increases in low-density lipoprotein cholesterol (LDL-C) and declines in HDL-C..$^{9,11,12}$ Small dense LDL particles have been explained within current smokers and developments in lipid levels after a smoking pause; yet, these results have been less consistent. ${ }^{13,14}$ Hitherto no studies have prospectively investigated the impacts of smoking and non-smoking on lipoproteins in a large population. This matter is very significant since smokers in the 21st century are remarkably more overweight than those studied beforehand. ${ }^{15}$ Given that smoking pause is related to weight gain ${ }^{16}$ and weight gain influences lipoproteins, the impacts of smoking stop on lipoproteins remains unspecified. ${ }^{17-20}$

\section{Objectives}

There is a paucity of knowledge on the level of cholesterol in smokers regarding gender differences in Nigeria. Many previous studies in the literature search are from the

Copyright (C 2021 The Author(s). This is an open-access article distributed under the terms of the Creative Commons Attribution License (http:// creativecommons.org/licenses/by/4.0), which permits unrestricted use, distribution, and reproduction in any medium, provided the original work is properly cited. 
Western world and none were from this region. Moreover, coupled with the fact that there are variant degrees of smoking habit, that we observe in Sagamu. National smoking cessation strategies in Nigeria are hindered by a lack of up-to-date epidemiologic data. However, there are $4 \%$ incidences of hyperlipidemia in Nigeria as demonstrated by some workers. ${ }^{21}$ The aim study aimed to determine the level of serum lipids among smokers and non-smokers and gender differences if any. This will serve as a basis for advice against the development of chronic heart disease (CHD) in the nearest future.

\section{Methods}

This study was conducted between March and September 2019 which involved a prospective cross-sectional selection of 100 inhabitants in Sagamu, Ogun State, SouthWest, Nigeria. Their ages were between 25 and 54 years. Hypertensive and diabetic subjects were exempted from this study because they were not part of the study groups. The study was carried out during the menstrual cycle in female subjects to eliminate the influence of female hormones on the collected data.

The weight of subjects was recorded in kilograms (to the nearest $1.0 \mathrm{~kg}$ ) without wearing any heavy clothing like a coat, jacket, shoes, or Agbada (a flowing wide-sleeved robe), using a calibrated bathroom scale (Soehnle Waagen GmbH and Co. KG, D 71540 Murrhardt/Germany) positioned on a firm horizontal surface.

Height of subjects was measured in meters (to the nearest $0.1 \mathrm{~m}$ ) using a stadiometer. Subjects stood erect, without shoes and headgears, on a flat surface with the heels and occiput in contact with the stadiometer (Prestige HM0016D) (India).

The bathroom weighing machine and stadiometer had the reliability test using Rasch modeling approach and Samuel Messick's method to test their validity.

The body mass index (BMI) was subsequently calculated using the formula: weight $(\mathrm{kg}) /$ height $^{2}\left(\mathrm{~m}^{2}\right)$. There were two groups of subjects [control (non-smokers) and test group (smokers)]. Estimation of blood lipid levels was conducted in each of the subjects as described below.

Blood samples were obtained after overnight fasting for determination of LP levels using standard methods at baseline, 2, 4 6, and 8 weeks, respectively. The LP determined from the fasting blood was measured spectrophotometrically utilizing standard laboratory kits supplied by BIOLABO, France. Data were analyzed using descriptive statistics and repeated measures analysis of variance (ANOVA) with significance set at $P<0.05$.

\subsection{Determination of Total Cholesterol}

TC level was measured spectrophotometrically using standard laboratory supplied by BIOLABO, France. The cholesterol formed reacts with oxygen in the presence of cholesterol oxidase to form 4-cholesten-3-one and hydrogen peroxide. The hydrogen peroxide formed reacts with phenol and 4-amino-antipyrine in the presence of peroxidase to give aminoneimine (pinkish in colour) and water. The intensity of the pink/red colour formed is proportional to the cholesterol concentration. It was performed according to standard protocols.

\subsection{Determination of HDL Cholesterol}

HDL-C level was measured spectrophotometrically using standard lab kits supplied by BIOLABO, France. LDL contained in serum are precipitated by the addition of phosphotungstic acid and magnesium chloride. High-density lipoproteins (HDL) which remain in the supernatant (obtained after centrifugation) react with the cholesterol reagent and proportionally with the cholesterol standard. It was conducted according to standard protocols.

Determination of TG and LDL levels were also carried out according to standard protocols.

The following definitions were utilized: BMI category includes: underweight: $\mathrm{BMI}<18.5 \mathrm{~kg} / \mathrm{m}^{2}$, normal weight: BMI 18.5-24.9 kg/m² overweight: BMI $25.0-29.9 \mathrm{~kg} / \mathrm{m}^{2}$ and obesity: BMI $\geq 30 \mathrm{~kg} / \mathrm{m}^{2}$ [WHO Expert ConsultationLancet (London, England) 2004]. ${ }^{22}$

Sample size determination method using the Cochran's formula:

$$
\begin{array}{ll}
\text { - } & \frac{\left(\mathrm{Z}_{1-\alpha} / 2\right)^{2} \mathrm{xSD}^{2}}{\mathrm{~d}^{2}}=\frac{1.96^{2}(25)^{2}}{5^{2}}=96 \\
\text { - } & \text { Where } \\
\text { - } & \mathrm{Z}=\text { normal variant } \\
\text { - } & \mathrm{d}=5 \%(\text { acceptable margin of error }) \\
\text { - } & \mathrm{SD}=25 \mathrm{mg} / \mathrm{dL} \text { from the previous study. }
\end{array}
$$

\subsection{Statistical Analysis}

The student $t$ test was used to compare variability between study and control groups as well as males and females. The data obtained were analyzed using the computer statistical programme package SPSS version 25.0 Probability value of $P$ value less than 0.05 was considered statistically significant.

\section{Results}

Fifty-one $(51.0 \%)$ of the participants in the study were between 25 and 34 years old. There were 24(48.0\%) smokers and $27(54.0 \%)$ non-smokers in the age group. There were 80 males and 20 females in the study group. Forty $(80.0 \%)$ males and $10(20.0 \%)$ females were smokers and $40(80.0 \%)$ males and $10(20.0 \%)$ were non-smokers. Two (4.0\%) smokers of the study group were obese while 4 $(8.0 \%)$ were non-smokers. Eighteen (36.0\%) smokers were overweight and 14 (28.0\%) non-smokers were overweight (Table 1).

The average TC of $198.71 \pm 2.30 \mathrm{mg} / \mathrm{dL}$ in smokers was significantly higher than $174.62 \pm 1.51 \mathrm{mg} / \mathrm{dL}$ in nonsmokers $(P<0.05)$. The mean HDL of $56.74 \pm 1.15 \mathrm{mg} / \mathrm{dL}$ in non-smokers was significantly higher than $40.87 \pm 1.32$ $\mathrm{mg} / \mathrm{dL}$ in smokers $(P<0.05)$ (Table 2$)$.

The average total cholesterol of $195.38 \pm 2.22 \mathrm{mg} / \mathrm{dL}$ in male smokers was significantly higher than $166.04 \pm 1.51$ 
$\mathrm{mg} / \mathrm{dL}$ in male non-smokers $(P<0.05)$. The mean HDL was $58.13 \pm 2.44 \mathrm{mg} / \mathrm{dL}$ in male non-smokers which was significantly higher than $40.26 \pm 1.70 \mathrm{mg} / \mathrm{dL}$ in male smokers $(P<0.05)$ (Table 3$)$.

The average TC of $203.47 \pm 5.54 \mathrm{mg} / \mathrm{dL}$ in female smokers was significantly higher than $183.56 \pm 3.61 \mathrm{mg} /$ $\mathrm{dL}$ in female non-smokers $(P<0.05)$. The mean HDL was $52.83 \pm 5.44 \mathrm{mg} / \mathrm{dL}$ in female non-smokers which was higher than $41.09 \pm 2.99 \mathrm{mg} / \mathrm{dL}$ in female smokers $P<0.05$ ) (Table 4).

\section{Discussion}

In this study, we found that the numbers of male smokers are higher than female smokers in the study groups. There were more overweight smokers than non-smokers. Conversely, there are fewer numbers of obese smokers. This may be due to the fact that many people smoke either at home or in the club house. Moreover, the male subjects have lower HDL-C than the females. The TC concentration is higher in female subjects than males whereas the TC and LDL-C are lower in female subjects. This may be due to the ability to handle lipids in males compared to females since there is a tendency for male subjects to engage more in exercise than females because naturally, females tend to engage in a more sedentary lifestyle. Smokers usually have the habit of staying in one place during smoking. They do not want many people to see them moving around. They stay either at club house or home performing the act.

According to Wilson et $\mathrm{al}^{23}$ the magnitude of the difference in HDL concentration between smokers and non-smokers is of the order of $0.06-0.22 \mathrm{mmol} / \mathrm{L}$, and in many studies, a sex difference was present with a larger effect being seen in women than in men. However, in this

Table 1. Demographic Characteristics of the Study Groups

\begin{tabular}{llccc}
\hline Variable & Category & Total (\%) & Smokers (\%) & Non-smokers (\%) \\
\hline \multirow{3}{*}{ Age (y) } & $25-34$ & $51(51.0)$ & $24(48.0)$ & $27(54.0)$ \\
& $35-44$ & $28(28.0)$ & $15(30.0)$ & $13(26.0)$ \\
& $45-54$ & $21(21.0)$ & $11(22.0)$ & $10(20.0)$ \\
Gender & Male & $80(80.0)$ & $40(80.0)$ & $40(80.0)$ \\
& Female & $20(20.0)$ & $10(20.0)$ & $10(20.0)$ \\
& Underweight & $0(0.0)$ & $0(0.0)$ & $0(0.0)$ \\
BMI $\left(\mathrm{kg} / \mathrm{m}^{2}\right)$ & Normal weight & $62(62.0)$ & $30(60.0)$ & $32(64.0)$ \\
& Overweight & $32(32.0)$ & $18(36.0)$ & $14(28.0)$ \\
& Obese & $6(6.0)$ & $2(4.0)$ & $4(8.0)$ \\
\hline
\end{tabular}

Table 2. Lipid Profile of the Study Group

\begin{tabular}{lcccc}
\hline $\begin{array}{l}\text { Variable } \\
(\mathbf{m g} / \mathbf{d L})\end{array}$ & Smokers $(\mathbf{n}=\mathbf{5 0})$ & $\begin{array}{c}\text { Non-smokers } \\
(\mathbf{n}=\mathbf{5 0})\end{array}$ & $\boldsymbol{t}$ & $\boldsymbol{P}$ \\
\hline TC & $198.71 \pm 2.30$ & $174.62 \pm 1.51$ & 8.756 & $0.000^{*}$ \\
TG & $162.55 \pm 4.13$ & $110.81 \pm 2.30$ & 10.945 & $0.000^{*}$ \\
HDL & $40.87 \pm 1.32$ & $56.74 \pm 1.15$ & 9.065 & $0.000^{*}$ \\
LDL & $141.54 \pm 2.88$ & $107.65 \pm 2.15$ & 9.430 & $0.000^{*}$ \\
\hline
\end{tabular}

*Significant at $P<0.05$ and the analysis by student $t$ test.
Table 3. Lipid Profile of the Male Study Group

\begin{tabular}{lcccc}
\hline $\begin{array}{l}\text { Variable } \\
(\mathbf{m g} / \mathbf{d L})\end{array}$ & $\begin{array}{c}\text { Smokers } \\
(\mathbf{n}=\mathbf{4 0})\end{array}$ & $\begin{array}{c}\text { Non-smokers } \\
(\mathbf{n}=\mathbf{4 0})\end{array}$ & $\boldsymbol{t}$ & $\boldsymbol{P}$ \\
\hline TC & $195.38 \pm 2.22$ & $166.04 \pm 1.51$ & 10.928 & $0.000^{*}$ \\
TG & $180.73 \pm 3.45$ & $108.45 \pm 1.63$ & 18.943 & $0.000^{*}$ \\
HDL & $40.26 \pm 1.70$ & $58.13 \pm 2.44$ & 6.009 & $0.000^{*}$ \\
LDL & $150.18 \pm 3.09$ & $110.22 \pm 1.95$ & 10.936 & $0.000^{*}$ \\
\hline
\end{tabular}

*Significant at $P<0.05$ and the analysis by student $t$ test.

Table 4. Lipid Profile of the Female Study Group

\begin{tabular}{lcccc}
\hline $\begin{array}{c}\text { Variable } \\
(\mathbf{m g} / \mathbf{d L})\end{array}$ & Smokers $(\mathbf{n}=\mathbf{1 0})$ & $\begin{array}{c}\text { Non-smokers } \\
(\mathbf{n}=\mathbf{1 0})\end{array}$ & $\boldsymbol{t}$ & $\boldsymbol{P}$ \\
\hline TC & $203.47 \pm 5.54$ & $183.56 \pm 3.61$ & 3.011 & $0.008^{*}$ \\
TG & $152.73 \pm 7.36$ & $112.41 \pm 4.00$ & 4.813 & $0.000^{*}$ \\
HDL & $41.09 \pm 2.99$ & $52.83 \pm 5.44$ & 1.891 & 0.075 \\
LDL & $140.33 \pm 5.93$ & $105.74 \pm 3.65$ & 4.968 & $0.000^{*}$ \\
\hline
\end{tabular}

*Significant at $P<0.05$ and the analysis by student $t$ test.

study, the difference in HDL-C was $5.87 \mathrm{mg} / \mathrm{dL}$ or 0.0587 $\mathrm{mmol} / \mathrm{L}$. For example, the Framingham study ${ }^{24}$ detected a smoker/non-smoker difference in HDL of $0.08 \mathrm{mmol} / \mathrm{L}$ for men and $0.13 \mathrm{mmol} / \mathrm{L}$ for women. ${ }^{25}$ Similarly, in this study we had $0.079 \mathrm{mmol} / \mathrm{L}$ for men and $0.117 \mathrm{mmol} / \mathrm{L}$ for women. In a study of a normal, healthy population, ${ }^{24}$ Framingham observed a $0.15 \mathrm{mmol} / \mathrm{L}$ discrepancy in HDL cholesterol and a $16 \mathrm{mg} / \mathrm{dL}$ difference in HDL2 after adjustment to confound the variables of lifestyle. In combination with changes in LDL levels, this gave rise to considerable increase in the mean LDL/HDL ratio 'atherogenic index' in smokers $(2.89 \pm 1.18)$ compared to non-smokers $(2.38 \pm 0.98)$ and, based on this index, cigarette smoking put $40 \%$ more individuals into the high-risk category of an LDL/HDL ratio $>4 .{ }^{25} \mathrm{HDL}$ is heterogeneous and exists as two main sub-fractions: large HDL2 (8.8-12.9 $\mathrm{nm})$ and small HDL3 (7.22-8.8 $\mathrm{nm})$. Some studies have found that the effects of smoking were largely confined to the HDL2 sub-fraction, ${ }^{25}$ while others have found substantial changes in HDL3 ${ }^{25}$ A study that examined the acute effect of smoking also reported a reduction mainly in the HDL3 subfraction. ${ }^{25}$

An enhancement in HDL-C was obvious in subgroups by sex, age, location, timing, study type, baseline HDL-C, baseline weight, and increase in weight was validated biochemically. ${ }^{26}$ Craig et al, found that quitting relevant to increased HDL-C, on the basis of within-subject changes is in line with remarkable proof of lower HDL-C levels in smokers than non-smokers. ${ }^{1}$ Notably, two large observational studies (KUSHIM, YEH) showed a decrease in HDL-C after quitting, and an even larger decline in continuing smokers and never smokers, ${ }^{22}$ Maeda et al, ${ }^{26}$ based on far fewer change estimates, observed notably $(P<0.05)$ higher increases in HDL-C for females than males. Although our assessment was also higher for females, we observed the discrepancy to be remarkable.

Smoking might decline HDL-C, however, the mechanism involved are not completely found out. 
One popular justification ${ }^{27}$ is that smoking changes catecholamine release, thus releasing free fatty acid which in turn influences VLDL and LDL concentrations to favour their agglomeration in blood, promoting a lower HDL concentration. However, other assumptions have been made ${ }^{28}$ including smoking enhancing cholesteryl ester transfer protein, declining lecithin cholesterol acyl-transferase activity, affecting apo-1 synthesis, or augmenting TG. It has also been proposed that some of the changes in HDL-C are because of associated changes in diet $^{29-32}$ but as pointed out above our analyses showed that the enhancement in HDL-C tended to be larger in nonsmokers compared to smokers. ${ }^{31,32}$

\subsection{Limitations}

Prospective study over years and inability to quantify the number of cigarette smoked over a long period of time and the other underlying health challenges in the subjects which were not identified at the time of study may confound variables. This is an interesting issue for future investigations. However, continuous research is required to validate our findings.

\section{Conclusion}

Smoking is clearly associated with a decrease in HDL-C concentrations. The HDL-C is lower in male smokers than females. The lipid levels of smokers obtained from this study can be utilized as a baseline for future study. This will serve as a basis for advice against the development of $\mathrm{CHD}$ in the nearest future.

\section{Authors' Contributions}

EOT: Conception, design, data collation, analysis, and manuscript writing. LOAT: Literature review, proofreading, and editing.

\section{Conflict of Interest Disclosures}

The authors declare that there is no conflict of interests.

\section{Ethical Approval}

Ethical clearance for the study was obtained from the Health Research Ethics Committee (HREC) of Olabisi Onabanjo University Teaching Hospital (OOUTH), Sagamu. All participants (100) of this study signed an informed consent form, in accordance with the committee regulations, before answering the questionnaire and taking their anthropometric measurements. The use of pro forma was adopted.

\section{References}

1. Craig WY, Palomaki GE, Haddow JE. Cigarette smoking and serum lipid and lipoprotein concentrations: an analysis of published data. BMJ. 1989;298(6676):784-788. doi:10.1136/ bmj.298.6676.784

2. US Surgeon General: The health benefits of smoking cessation. A report of the Surgeon General: US Department of Health and Human Services, Public Health Service, Centers for Disease Control, Center for Chronic Disease Prevention and Health

\section{Research Highlights}

\section{What Is Already Known?}

It has long been known that smokers have a lower concentration of high-density lipoprotein cholesterol (HDL-C) than do non-smokers. The mechanisms by which smoking increases CVD risk appear to be multifactorial and incompletely understood and smoking alters catecholamine release. Since smoking cessation is associated with weight gain and weight gain affects lipoproteins and also Quitting smoking is associated with the increase in HDL-C.

\section{What Does This Study Add?}

- In this study, we found that the numbers of male smokers are higher compared to female smokers in the study groups.

- There were more overweight smokers than nonsmokers. Conversely, there are fewer numbers of obese smokers.

- Smoking is associated with a decrease in HDL-C.

- HDL-C is however lower in male smokers than female smokers.

Promotion. Rockville, Maryland: Office on Smoking and Health; 1990. DHHS Publication No. (CDC) 90-8416. 3.

3. US Surgeon General: The health consequences of smoking. A report of the Surgeon General. Atlanta, Georgia: US Department of Health and Human Services, Centers for Disease Control and Prevention, National Center for Chronic Disease Prevention and Health Promotion, Office on Smoking and Health; 2004.

4. Smoking-attributable mortality, years of potential life lost, and productivity losses--United States, 2000-2004. MMWR Morb Mortal Wkly Rep. 2008;57(45):1226-1228.

5. American Heart Association. Heart Disease and Stroke Statistics--2009 Update. Dallas, TX: American Heart Association; 2009

6. Doll R, Peto R, Boreham J, Sutherland I. Mortality in relation to smoking: 50 years' observations on male British doctors. BMJ 2004;328(7455):1519. doi:10.1136/bmj.38142.554479.AE.

7. Freund KM, Belanger AJ, D'Agostino RB, Kannel WB. The health risks of smoking. The Framingham study: 34 years of followup. Ann Epidemiol. 1993;3(4):417-424. doi:10.1016/10472797(93)90070-k.

8. Ambrose JA, Barua RS. The pathophysiology of cigarette smoking and cardiovascular disease: an update. J Am Coll Cardiol. 2004;43(10):1731-1737. doi:10.1016/j.jacc.2003.12.047.

9. Gossett LK, Johnson HM, Piper ME, Fiore MC, Baker TB, Stein $\mathrm{JH}$. Smoking intensity and lipoprotein abnormalities in active smokers. J Clin Lipidol. 2009;3(6):372-378. doi:10.1016/j. jacl.2009.10.008.

10. Benowitz NL. Cigarette smoking and cardiovascular disease: pathophysiology and implications for treatment. Prog Cardiovasc Dis. 2003;46(1):91-111. doi:10.1016/s00330620(03)00087-2.

11. Chelland Campbell S, Moffatt RJ, Stamford BA. Smoking and smoking cessation -- the relationship between cardiovascular disease and lipoprotein metabolism: a review. Atherosclerosis. 2008;201(2):225-235. doi:10.1016/j. atherosclerosis.2008.04.046.

12. Criqui $M H$, Wallace RB, Heiss G, Mishkel M, Schonfeld 
G, Jones GT. Cigarette smoking and plasma high-density lipoprotein cholesterol. The Lipid Research Clinics Program Prevalence Study. Circulation. 1980;62(4 Pt 2):IV70-76.

13. Griffin BA, Freeman DJ, Tait GW, et al. Role of plasma triglyceride in the regulation of plasma low density lipoprotein (LDL) subfractions: relative contribution of small, dense LDL to coronary heart disease risk. Atherosclerosis. 1994;106(2):241253. doi:10.1016/0021-9150(94)90129-5.

14. Urahama N, Iguchi G, Shimizu M, Fujihira K, Kobayashi S, Baba H. Smoking and small, dense low-density lipoprotein particles: cross-sectional study. Nicotine Tob Res. 2008;10(8):13911395. doi:10.1080/14622200802238852.

15. State-specific prevalence of obesity among adults--United States, 2007. MMWR Morb Mortal Wkly Rep. 2008;57(28):765768.

16. Eisenberg D, Quinn BC. Estimating the effect of smoking cessation on weight gain: an instrumental variable approach. Health Serv Res. 2006;41(6):2255-2266. doi:10.1111/j.14756773.2006.00594.x.

17. Johnson HM, Gossett LK, Piper ME, et al. Effects of smoking and smoking cessation on endothelial function: 1-year outcomes from a randomized clinical trial. J Am Coll Cardiol. 2010;55(18):1988-1995. doi:10.1016/j.jacc.2010.03.002.

18. Flegal KM, Troiano RP, Pamuk ER, Kuczmarski RJ, Campbell SM. The influence of smoking cessation on the prevalence of overweight in the United States. N Engl J Med. 1995;333(18):1165-1170. doi:10.1056/ nejm199511023331801.

19. Dattilo AM, Kris-Etherton PM. Effects of weight reduction on blood lipids and lipoproteins: a meta-analysis. Am J Clin Nutr. 1992;56(2):320-328. doi:10.1093/ajcn/56.2.320.

20. Hession M, Rolland C, Kulkarni U, Wise A, Broom J. Systematic review of randomized controlled trials of low-carbohydrate vs. low-fat/low-calorie diets in the management of obesity and its comorbidities. Obes Rev. 2009;10(1):36-50. doi:10.1111/ j.1467-789X.2008.00518.x.

21. Akpa MR, Agomouh DI, Alasia DD. Lipid profile of healthy adult Nigerians in Port Harcourt, Nigeria. Niger J Med. 2006;15(2):137-140. doi:10.4314/njm.v15i2.37097.

22. Appropriate body-mass index for Asian populations and its implications for policy and intervention strategies. Lancet. 2004;363(9403):157-163. doi:10.1016/s01406736(03)15268-3.
23. Wilson PW, Garrison RJ, Abbott RD, Castelli WP. Factors associated with lipoprotein cholesterol levels. The Framingham study. Arteriosclerosis. 1983;3(3):273-281. doi:10.1161/01. atv.3.3.273.

24. Freeman DJ, Griffin BA, Murray E, et al. Smoking and plasma lipoproteins in man: effects on low density lipoprotein cholesterol levels and high density lipoprotein subfraction distribution. Eur J Clin Invest. 1993;23(10):630-640. doi:10.1111/j.1365-2362.1993.tb00724.x.

25. Haffner SM, Applebaum-Bowden D, Wahl PW, et al. Epidemiological correlates of high density lipoprotein subfractions, apolipoproteins A-I, A-II, and D, and lecithin cholesterol acyltransferase. Effects of smoking, alcohol, and adiposity. Arteriosclerosis. 1985;5(2):169-177. doi:10.1161/01. atv.5.2.169.

26. Maeda K, Noguchi Y, Fukui T. The effects of cessation from cigarette smoking on the lipid and lipoprotein profiles: a metaanalysis. Prev Med. 2003;37(4):283-290. doi:10.1016/s00917435(03)00110-5.

27. Benowitz NL. Drug therapy. Pharmacologic aspects of cigarette smoking and nicotine addiction. $N$ Engl J Med. 1988;319(20):1318-1330. doi:10.1056/ nejm198811173192005.

28. Freeman DJ, Packard CJ. Smoking and plasma lipoprotein metabolism. Clin Sci (Lond). 1995;89(4):333-342. doi:10.1042/ cs0890333.

29. Masarei JR, Puddey IB, Vandongen R, Beilin LJ, Lynch WJ. Effect of smoking cessation on serum apolipoprotein A-I and A-II concentrations. Pathology. 1991;23(2):98-102. doi:10.3109/00313029109060805.

30. Quensel $M$, Söderström A, Agardh CD, Nilsson-Ehle P. High density lipoprotein concentrations after cessation of smoking: the importance of alterations in diet. Atherosclerosis. 1989;75(2-3):189-193. doi:10.1016/0021-9150(89)90176-7.

31. Stamford BA, Matter S, Fell RD, Papanek P. Effects of smoking cessation on weight gain, metabolic rate, caloric consumption, and blood lipids. Am J Clin Nutr. 1986;43(4):486-494. doi:10.1093/ajen/43.4.486.

32. Stubbe I, Eskilsson J, Nilsson-Ehle P. High-density lipoprotein concentrations increase after stopping smoking. Br Med J (Clin Res Ed). 1982;284(6328):1511-1513. doi:10.1136/ bmj.284.6328.1511. 